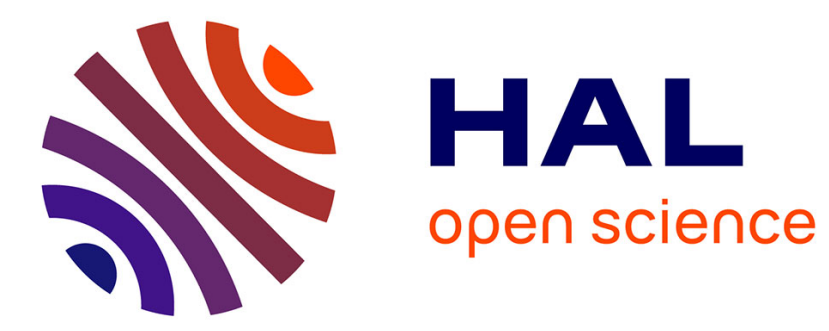

\title{
MAGNETIC PROPERTIES OF VFe ALLOYS
}

P. Pataud, J. Perrier, R. Tournier

\section{To cite this version:}

P. Pataud, J. Perrier, R. Tournier. MAGNETIC PROPERTIES OF VFe ALLOYS. Journal de Physique Colloques, 1974, 35 (C4), pp.C4-189-C4-193. 10.1051/jphyscol:1974433 . jpa-00215624

\section{HAL Id: jpa-00215624 https://hal.science/jpa-00215624}

Submitted on 1 Jan 1974

HAL is a multi-disciplinary open access archive for the deposit and dissemination of scientific research documents, whether they are published or not. The documents may come from teaching and research institutions in France or abroad, or from public or private research centers.
L'archive ouverte pluridisciplinaire HAL, est destinée au dépôt et à la diffusion de documents scientifiques de niveau recherche, publiés ou non, émanant des établissements d'enseignement et de recherche français ou étrangers, des laboratoires publics ou privés. 


\title{
MAGNETIC PROPERTIES OF VFe ALLOYS
}

\author{
P. PATAUD, \\ Institut Max Von Laue-Paul Langevin, BP 156, \\ 38042 Grenoble, France \\ and \\ J. P. PERRIER, R. TOURNIER, \\ Centre de Recherches sur les Très Basses Températures \\ Cedex 166, 38042 Grenoble Gare, France
}

\begin{abstract}
Résumé. - On a mesuré les aimantations isothermes des alliages de Vanadium-Fer jusqu'à une concentration atomique de Fer de $33 \%$, en insistant particulièrement sur les propriétés magnétiques des échantillons dont la concentration est proche de celle où le ferromagnétisme devient observable $(22 \%$ at. $\mathrm{Fe})$. L'analyse de la constante de Curie et de l'aimantation à saturation montre que le magnétisme est dû à des moments géants de valeur moyenne $20 \mu_{\mathrm{B}}$. Les températures d'ordre $T_{\mathrm{c}}$ et les températures de Curie $\theta_{\mathrm{p}}$ ont été mesurées ainsi que les susceptibilités finales des échantillons saturés, dont la variation avec la concentration en Fer s'explique par un phénomène de renforcement d'échange.

Abstract. - We have measured the degree of magnetization of VFe alloys up to $33 \%$ at. Fe with particular emphasis on the concentrations where ferromagnetism appears $(22 \%)$. The values of the Curie constant and of the saturation magnetization can be interpreted in terms of giant moments of about $20 \mu_{\mathrm{B}}$. The ordering temperature $T_{\mathrm{c}}$ and the paramagnetic Curie temperature $\theta_{\mathrm{p}}$ were measured. The variation with the concentration of iron of the high field susceptibility indicates the occurrence of exchange enhancement effects, as observed in systems with isolated impurities.
\end{abstract}

1. Introduction. - In some systems where the isolated transition impurities ( $\mathrm{Fe}, \mathrm{Co}, \mathrm{Ni}$ ) diluted in a non-magnetic host do not carry any magnetic moment, ferromagnetism may sometimes be observable over a certain value of the concentration. In the region of transition, the magnetization is highly inhomogeneous and giant moments are present. Such behaviour has been observed in some solid solutions of nickel where the critical concentrations of $\mathrm{Ni}$ are about $44 \%$ for $\mathrm{CuNi}$ [1] $63 \%$ for $\mathrm{RhNi}$ [2] and $87 \%$ for VNi [3]. $\overline{\text { We }}$ present a systematic study of the properties of the vanadium iron system. We will show that giant moments exist, similar to the case of the nickel-based alloys, together with polarization and exchange enhancement effects.

2. Experiments. - Appropriate quantities of iron and vanadium are melted in vacuum in an HF furnace, cast from the melt in a water-cooled copper mould, Then heated again in vacuum at a temperature just below the melting point and quenched in water.

The measurements of the magnetization at constant temperature were performed using the extraction method. Two sets of apparatus were necessary for each sample in order to cover the whole range of magnetic fields: a copper solenoid produced the fields ranging from 2 Oe to $2000 \mathrm{Oe}$, and a superconducting coil was used to produce the fields ranging from $2 \mathrm{kOe}$ to $50 \mathrm{kOe}$. The measurements in high fields were performed at the lowest available tempe- rature $0.07 \mathrm{~K}$ in order to obtain saturation, while the low field data were studied $v s$. temperature (the maximum range was $0.05<T<120$ ).

3. Experimental results. - The magnetization in high fields and low temperatures may be represented as the superposition of a saturated and of a nonsaturated part characterized by a field independent susceptibility (Fig. 1).

$$
M(T)=M_{0}(T)+\chi_{0}(T) H
$$

where $M_{0}(T)$ and $\chi_{0}(T)$ depend very slightly on the temperature. The magnetization $M_{0}(T=0)$ is hereafter called $\sigma_{0}$.

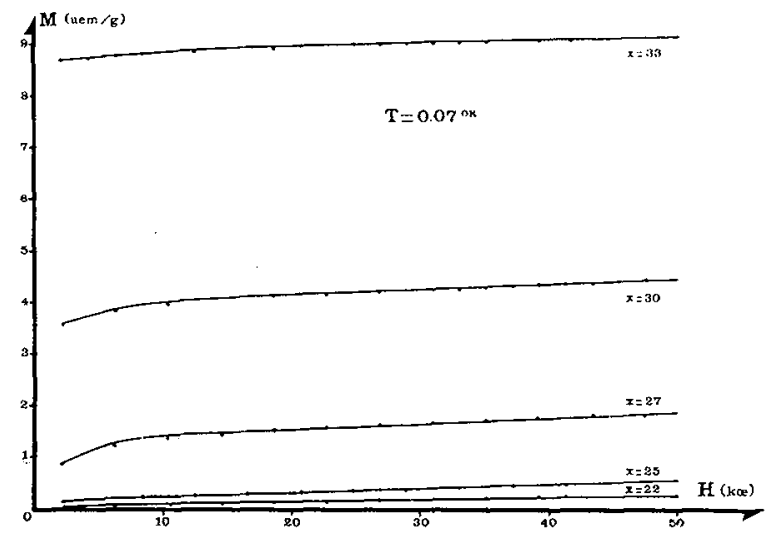

Frg. 1. - High field magnetization at each concentration $x \%$ at. $\mathrm{Fe}$. 


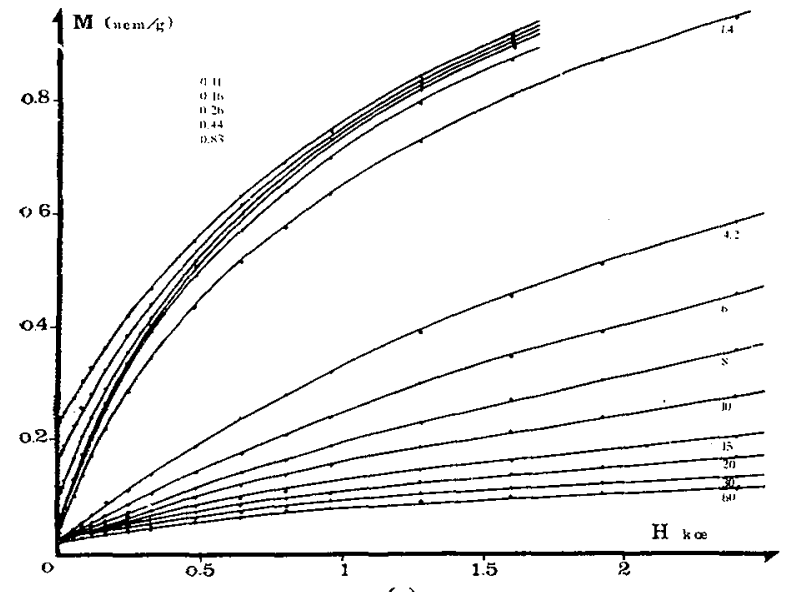

(a)

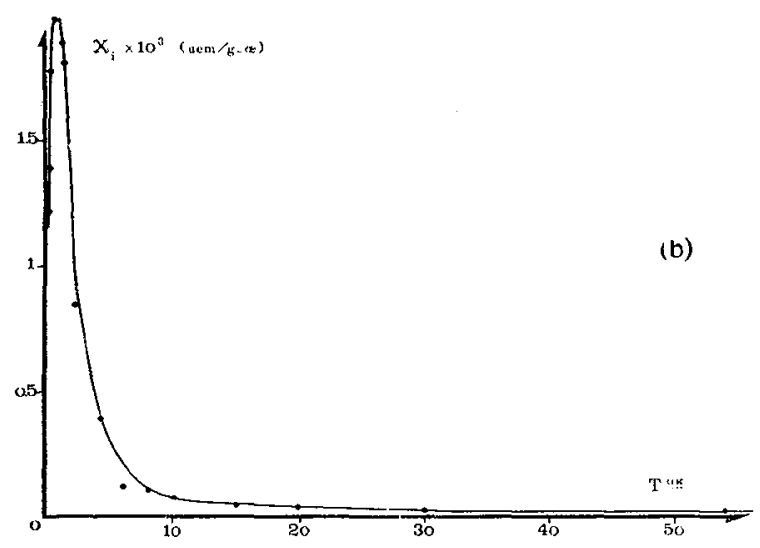

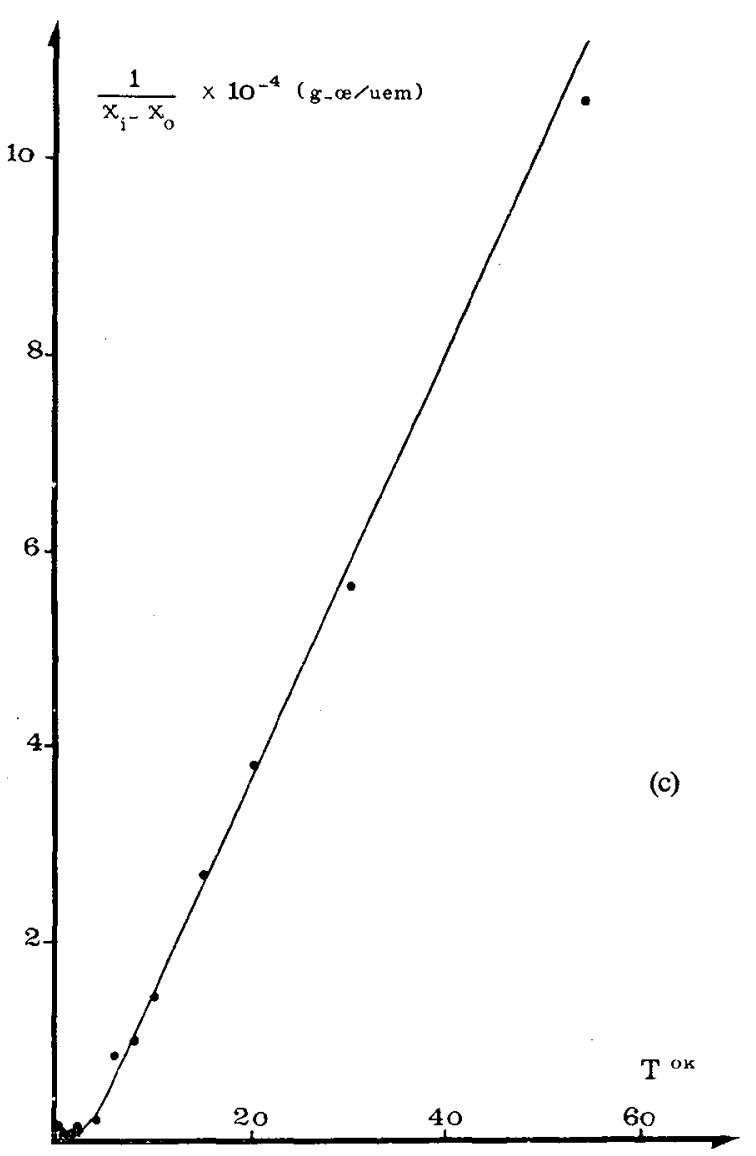

FIG. 2. - Magnetic properties of $x=27 \%$ at. Fe : a) low field magnetization at each temperature ; $b$ ) initial susceptibility vs. temperature ; c) experimental Curie Weiss Law.

Concerning the low field data, we define an initial susceptibility $\chi_{i}$ as the initial slope of the magnetization curves (as shown in Fig. $2 a$ for the case of the $27 \%$ ). The variation of $\chi_{i}$ with temperature is characterized by a peak arising at a certain temperature $T_{\mathrm{c}}$ (as shown in Fig. $2 b$ for the case of the $27 \%$ ), the ordering temperature of the considered alloy. For $T>T_{\mathrm{c}}$ the susceptibility can be represented by the following equation :

$$
\chi_{\mathrm{i}}=\frac{C}{T-\theta_{p}}+\chi_{0}
$$

where $\chi_{0}$ is the paramagnetic susceptibility previously defined in eq. (1), from which we can determine the

TABLE I

\begin{tabular}{|c|c|c|c|c|c|c|}
\hline$x \%$ at. $\mathrm{Fe}$ & (emu. ${ }^{\sigma_{0}}{ }^{-1}$ ) & 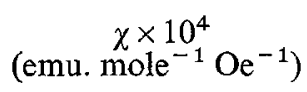 & (emu. $\mathrm{g}^{-1} \stackrel{C}{\mathrm{Oe}^{-1} \text { deg.) }}$ & $\begin{array}{c}\theta_{\mathrm{p}} \\
(\mathrm{deg})\end{array}$ & $\begin{array}{c}T_{\mathrm{c}} \\
\text { (deg.) }\end{array}$ & $\begin{array}{c}G \\
\left(\mu_{\mathrm{B}}\right)\end{array}$ \\
\hline - & - & - & 一 & - & - & - \\
\hline 0 & - & 3.204 & - & 一 & 一 & - \\
\hline 6 & 一 & 2.869 & - & 一 & 一 & 一 \\
\hline 10 & - & 2.711 & - & - & 一 & 一 \\
\hline 15 & - & 2.455 & - & - & 一 & - \\
\hline 20 & 一 & 2.508 & 一 & 一 & 一 & - \\
\hline 22 & 0.056 & 2.549 & $9.02 \times 10^{-6}$ & -0.2 & 一 & 7.6 \\
\hline 25 & 0.194 & 3.339 & $5.62 \times 10^{-5}$ & 0 & 0.1 & 13.2 \\
\hline 27 & 1.35 & 5.488 & $4.52 \times 10^{-4}$ & 3.5 & 0.8 & 13.3 \\
\hline 30 & 3.98 & 4.901 & $2.13 \times 10^{-3}$ & 17.5 & 6 & 20.6 \\
\hline 33 & 8.91 & 3.285 & $6.45 \times 10^{-3}$ & 52 & 20 & 28.8 \\
\hline
\end{tabular}


Curie constant $C$ and the Curie temperature $\theta_{\mathrm{p}}$ for each alloy (see Fig. $2 c$ for the case of the $27 \%$ ).

$C$ and $\sigma_{0}$ can now be analysed in a classical way assuming that we are dealing with an assembly of $N_{g}$ identical magnetic moments $G$; Thus we have :

$$
\sigma_{0}=N_{g} G \quad C=\frac{N_{g} G^{2}}{3 k_{\mathrm{B}}}
$$

the values of $G$ deduced from eq. (3) are listed in Table I for each nominal concentration $x$ together with the values of $\sigma_{0}, C, \chi_{0}, \theta_{\mathrm{p}}, T_{\mathrm{c}}$. Giant moments, varying between 7 and $30 \mu_{\mathrm{B}}$, are obtained when $x$ increases from $22 \%$ to $33 \%$.

4. Occurrence of ferromagnetism. - The existence of giant moments indicates that the iron atoms do not all play the same role. Using the same analysis as proposed by Perrier et al. [4] for $\mathrm{CuNi}$, we shall assume that iron atoms which have a minimum number of other iron atoms in their first neighbouring shell are magnetic, and carry $2.22 \mu_{\mathrm{B}}$ (as in pure iron), and that two magnetic iron atoms belong to the same giant moment if they have at least one common first neighbouring site. A slight modification had to be performed in our case. In the vanadium lattice (which is b. c. c.) the first shell and the central atom have no first neighbour in common, so the above criterion would exclude the first neighbour shell from the giant moment, a situation which seems unreasonable. In order to avoid this difficulty we used for the calcu-

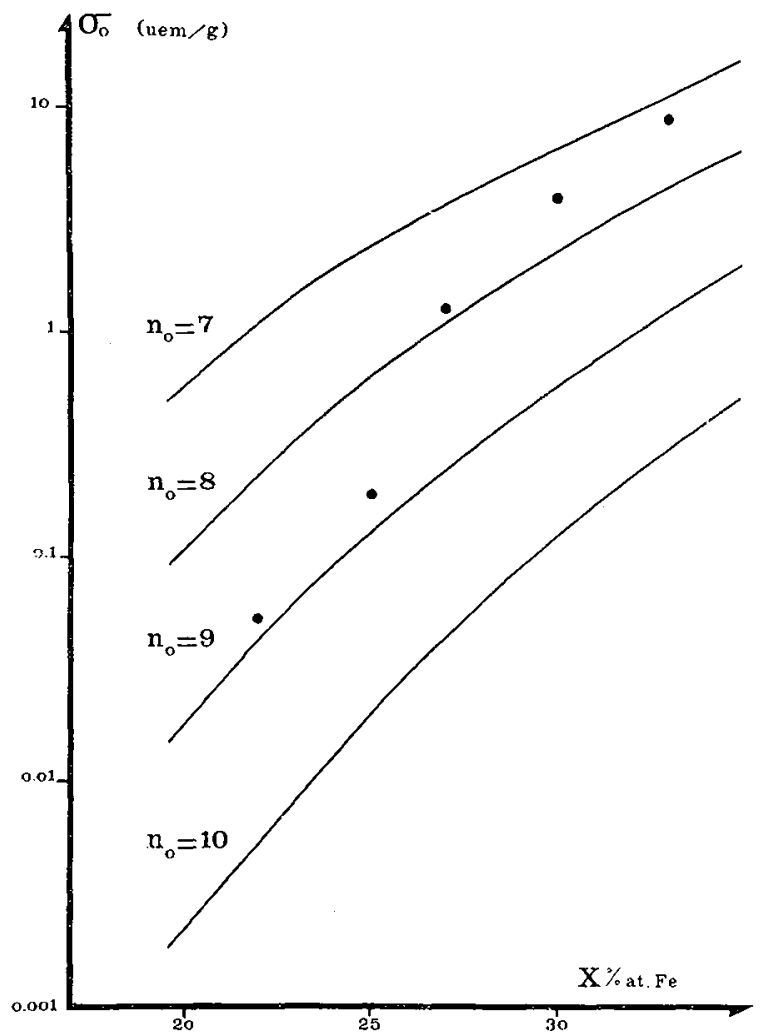

FIG. $3 a$.
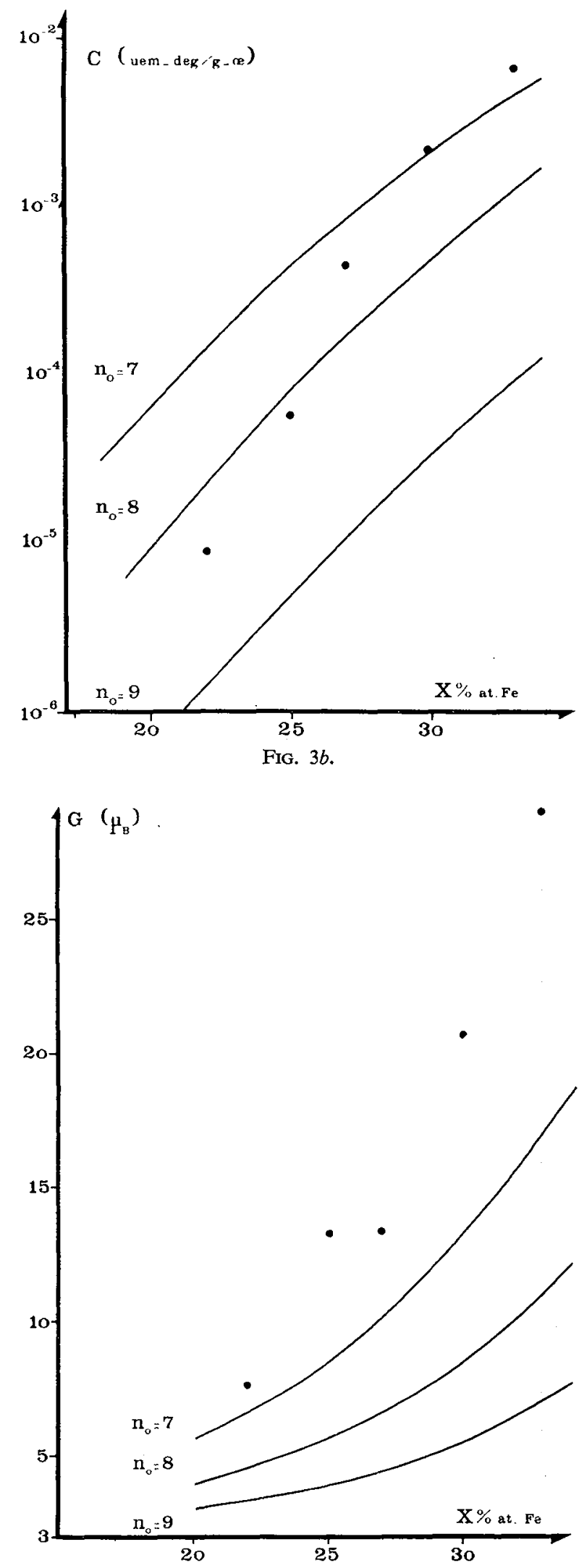

FIG. $3 c$.

Frg. 3. - Comparison with the model : a) Saturation magnetization $v s$. concentration ; $b$ ) Curie constant $v s$. concentration ; c) Moment values vs: concentration. 
lations a super shell which includes the 8 sites of the first shell and the 6 sites of the second shell.

Figure 3 shows the results of the calculations of $C$, $\sigma_{0}$, and $G$ (together with the experimental points) for different values of the minimum number $n_{0}$ of iron atoms on the super shell. The calculations are restricted to perfectly disordered alloys for which the saturation magnetization is given by the following formula :

$$
\sigma_{0}(x)=N_{\mathrm{t}}(x) \mu_{\mathrm{F}} x \sum_{n=n_{0}}^{n_{m}} C_{n_{m}}^{n} x^{n}(1-x)^{n_{m}-n}
$$

where $N_{\mathrm{t}}$ is the total number of atoms in a unit mass of alloy and $\mu_{\mathrm{F}}$ is the magnetic moment of iron $\left(\mu_{\mathrm{F}}=2.22 \mu_{\mathrm{B}}\right)$. Values of $G$ and $C$ are deduced from (4) in the same way as those in ref. [4]. The value $n_{0}=8$ seems to be a reasonable choice to describe the magnetic properties of the less concentrated alloys.

5. Nearly magnetic behaviour. - At each concentration the atoms of iron which are not magnetic but where the condition of magnetism is close to realized (for example when they have $n_{0}-1$ or $n_{0}-2$ near neighbours of iron) have a certain probability of having a magnetic atom in their vicinity and of experiencing a polarization from this atom. They may then contribute to the saturation magneti-

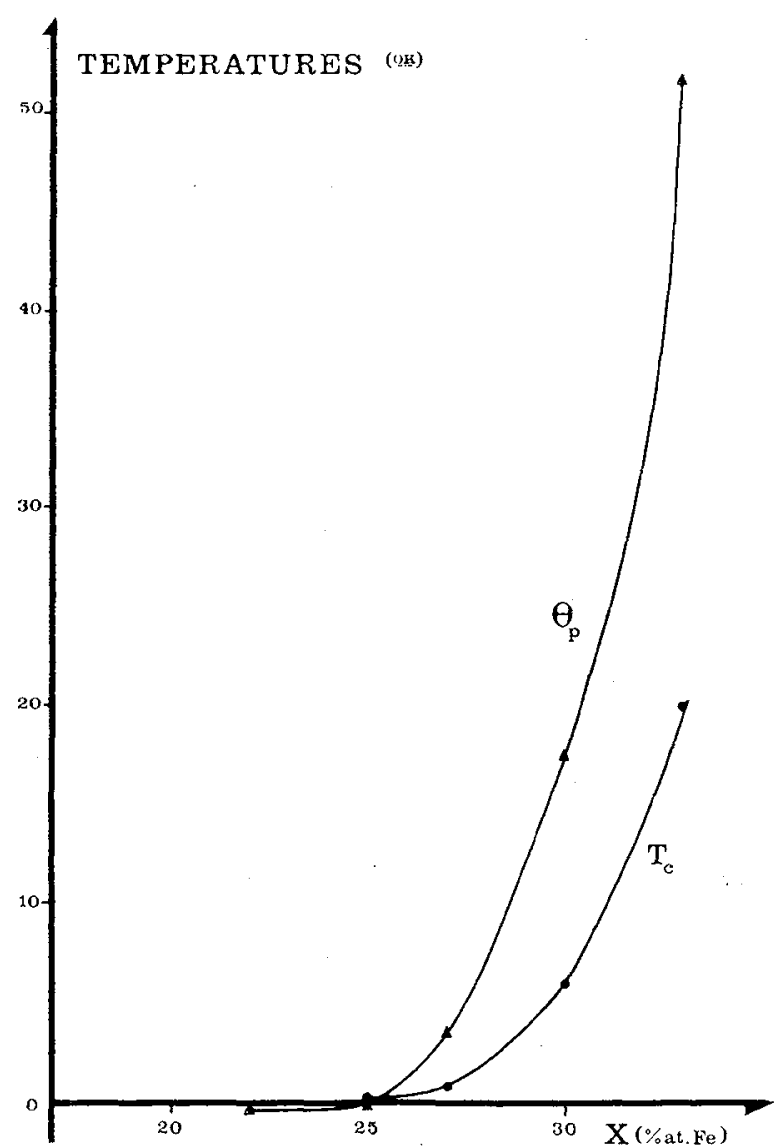

FIG. 4, - Ordering temperatures $T_{\mathrm{c}}$ and paramagnetic Curie temperatures $\theta_{\mathrm{p}}$. zation in moderately high fields and enhance the giant moments in low fields. This effect is increased when the concentration is raised. The systematic shift towards higher values of $n_{0}$ illustrated in figure 3 for increasing values of $x$ can thus be interpreted in favour of the existence of a class of polarized iron atoms by analogy with what has been observed in $\mathrm{PdNi}$ and PdNiFe alloys [5]. The existence of such a class of iron atoms is strongly supported by the fact that the samples with very low ordering temperature $(22 \%$ and $25 \%$ ) are not easily saturated. It must be noticed at this point that the paramagnetic Curie temperature becomes negative when the concentration is lowered to $22 \%$ (Fig. 4).

6. Non magnetic behaviour. - There are two main factors contributing to the non magnetic susceptibility $\chi_{0}$ : a spin susceptibility $\chi_{\mathrm{d}}$ and an orbital susceptibility $\chi_{\mathrm{vv}}$.

If we assume that the determination of the density of states from the susceptibility and the electronic specific heat in the framework of the theory of free electrons should give the same result in pure vanadium $\left(n_{\chi}\left(E_{\mathrm{F}}\right)=n_{\gamma}\left(E_{\mathrm{F}}\right)\right)$ we obtain $\chi_{\mathrm{vv}}=1.9 \times 10^{-4}$, a value which does not vary very much upon alloying according to different authors $[7,8]$. Supposing $\chi_{\mathrm{vv}}$ is constant we have plotted $n\left(E_{\mathrm{F}}\right)$ vs. $x$ in figure 5 . We observe that both quantities remain equal for

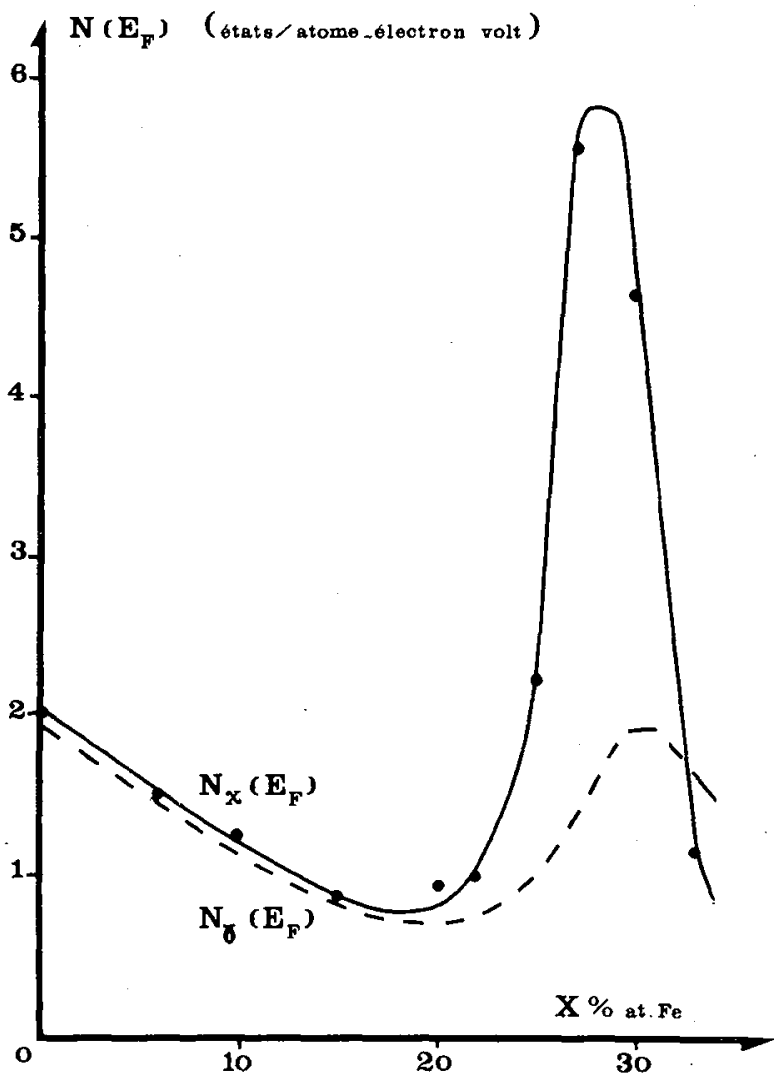

FIG. 5. - Comparison between effective densities of states at the Fermi level $n \chi\left(E_{\mathrm{F}}\right)$ and $n \gamma\left(E_{\mathrm{F}}\right)$ deduced respectively from $\chi \mathrm{d}$ and $\gamma$. 
$x<20 \%$ and are lower than the initial value, a variation which can be accounted for in terms of a variation of the average density of states. When $x$ is increased above $20 \%$, both $n_{x}$ and $n_{y}$ are increased and reach a maximum at about the same concentration. The ratio of the enhancements $\xi=n_{\gamma} / n_{z}$ being found is of the order of 0.3 at the maximum of the peaks. This decrease of $\xi$ from 1 to 0.3 when we come close to the magnetic condition agrees well with the predictions of Caroli, Lederer and Saint-James [9], who expect, from the theory of spin fluctuations (one impurity model) $\xi$ to vary between $\frac{3}{2}$ and $\frac{3}{2}(2 l+1)$ in the limit of strong Hund's coupling, this latter case corresponding to the magnetic case.
7. Conclusion. - It appears from the Curie constants and from the saturation magnetization values of our samples that magnetic clusters are present when ferromagnetism appears. The existence of polarized iron atoms (which carry a magnetic moment only when an external field is applied) has been shown in the less concentrated alloys. Together with this behaviour, the alloys have properties similar to those deduced from the localized spin fluctuation theory of isolated magnetic impurities in a non magnetic host ; these properties are typically an exchange enhancement ratio $\xi=0.3$ and a negative paramagnetic Curie temperature for the less concentrated alloys.

\section{References}

[1] Kouvel, J. S. and Comly, J. B., Phys. Rev. Lett. 24 (1970) 598.

[2] Hahn, A. and Wohfarth, E. P., Heb. Phys. Acta 41 (1968) 857.

[3] Amamou, A. and Loegel, B., J. Phys. F 3 (1973) L 79.

[4] Perrier, J. P., Tissier, B. and Tournier, R., Phys. Rev. Lett. 24 (1970) 313.

[5] Chouteau, C., Manhes, B. and Tournier, R., Proceedings of LT 11 St-Andrews, 2 (1968) 1316.
[6] Cheng, C. H., Wex, C. T. and Beck, P. A., Phys. Rev. 120 (1960) 426.

[7] Devos, J., J. Phys. \& Chem. Solids 33 (1972) 31.

[8] Lam, D. J., Van Osterburg, D. O., Nevitt, M. V., Trapp, H. D. and Pracht, D. W., Phys. Rev. 131 (1963) 1428.

[9] Caroli, B., Lederer, P., SAint-James, D., Phys. Rev, Lett. 23 (1969) 700. 